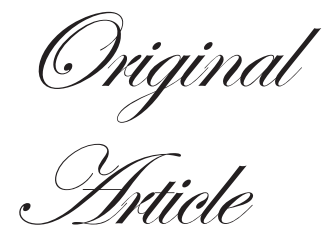

\title{
A series on intestinal strongyloidiasis in immunocompetent and immunocompromised hosts
}

\author{
Ujjala Ghoshal, ${ }^{1}$ Sonali Khanduja, ${ }^{1}$ Nabamita Chaudhury, ${ }^{1}$ Dinesh \\ Gangwar, ${ }^{1}$ Uday C Ghoshal ${ }^{2}$
}

\begin{abstract}
Departments of Microbiology ${ }^{1}$ and
Gastroenterology, ${ }^{2}$

Sanjay Gandhi Post Graduate

Institute of Medical Sciences,

Lucknow - 226014, India

\section{Correspondence:}

Dr. Ujjala Ghoshal

Email: ujjalaghoshal@yahoo.co.in
\end{abstract}

\section{ABSTRACT}

Background: Strongyloidiasis, endemic in tropical areas, may be asymptomatic in immunocompetent subjects or may cause potentially fatal hyper-infection in immunocompromised patients.

Methods: Of the 13,885 patients referred to the parasitology laboratory at our tertiary care referral center for stool microscopy, 15 were diagnosed as strongyloidiasis over a 6 year period. We assessed these patients retrospectively.

Results: Most patients were young (median age 32 years, range 3-66) males (12, 80\%). Seven patients (46.6\%) were immunocompromised. All patients were symptomatic, and symptoms included chronic diarrhea $(4,26.7 \%)$, acute diarrhea $(1,6.7 \%)$, abdominal pain $(6,40 \%)$, weight loss $(3,20 \%)$, cough $(2,13.33 \%)$, vomiting $(1,6.7 \%)$, anemia $(10,66.7 \%)$ and eosinophilia (3, $20 \%)$. Thirteen patients (86.6\%) were diagnosed on first stool microscopy. Duodenal biopsy showed normal histology in twelve (80\%) and partial villous atrophy in one (6.7\%) patient. Stool microscopy also revealed giardiasis and cryptosporidiosis in one patient each. Nine patients responded well to ivermectin and albendazole, one died and five were lost to followup.

Conclusions: In endemic areas, even immunocompetent subjects may suffer from symptomatic strongyloidiasis and associated eosinophilia is uncommon.

KEYWORDS: chronic diarrhea, villous atrophy, parasite, eosinophilia

\section{Introduction}

Strongyloides stercoralis is a nematode endemic in tropical and subtropical areas. ${ }^{1}$ Infected individuals may remain asymptomatic, but fatal illness or disseminated strongyloidiasis may develop in immunocompromised hosts. Strongyloidiasis may present with indigestion, abdominal pain, vomiting, chronic diarrhea, protein losing enteropathy and weight loss. Since symptoms of strongyloidiasis are often non-specific, it is rarely suspected or diagnosed clinically. Strongyloidiasis may be suspected by the clinicians in presence of peripheral blood eosinophilia. However, eosinophilia may not occur in hyper-infection, particularly in immunocompromised hosts. Immunocompromised states associated with strongyloidiasis include acquired immunodeficiency syndrome, chronic corticosteroid treatment, and organ transplantation such as kidney, liver, bone marrow transplantation, as these patients receive multiple immunosuppressive drugs. Hence, we performed a retrospective analysis on 15 consecutive patients with Strongyloides stercoralis infestation diagnosed by stool microscopy in the Department of Microbiology of our tertiary care referral center with the aim to evaluate: (i) frequency of 
immunocompetent or immunocompromised states among patients with strongyloidiasis, and (b) peripheral blood eosinophilia among patients with strongyloidiasis with or without immunocompromised states.

\section{Methods}

Data collection

All patients diagnosed with strongyloidiasis on stool microscopy at our parasitology laboratory over a 6 year period from April 2004 to July 2010, were included in this study. The demographic, clinical and laboratory data of the patients were collected from the electronic hospital information system and/ or case records.

\section{Laboratory procedures}

Each patient underwent stool microscopy using direct wet mount technique. An attempt was made to examine three consecutive stool specimens until the diagnosis of intestinal strongyloidiasis could be confirmed. Normal saline and iodine preparation were used for stool examination. Peripheral blood was examined for total and differential leukocyte count; an absolute eosinophil count greater than 400 cells $/ \mathrm{mm}^{3}$ was considered as eosinophilia. Disseminated infection was diagnosed from case records if a patient had evidence of extraintestinal involvement.

\section{Treatment and follow-up}

All strongyloidiasis patients were treated either with ivermectin (6 mg twice daily for 6 days in an immunocompromised host and for five days in an immunocompetent host) or albendazole (400 mg twice daily for 3 days). The follow-up data of patients were retrieved from hospital records. Stool microscopy was repeated on follow-up in patients consenting for it.

\section{Data analysis}

The data collected were analyzed using SPSS version 15.0.

\section{Results}

Demographic and clinical parameters

$15 / 13,885(0.1 \%)$ patients who underwent stool microscopy at our laboratory were found to have strongyloidiasis. Most patients were young (median age 32 years, range 3 to 66) males $(12 / 15,80 \%)$.

Of fifteen patients, 7 (46.6\%) were immunocompromised; 6 were on corticosteroids and one was infected with human immunodeficiency virus. All the patients were symptomatic and the symptoms included chronic diarrhea ( $>4$ weeks duration) in four (26.7\%), acute diarrhea in one $(6.7 \%)$, abdominal pain in six (40\%), weight loss in three (20\%), cough in two $(13.3 \%)$ and vomiting in one $(6.7 \%)$. Ten patients $(66.7 \%)$ had anemia and three (20\%) had eosinophilia.

\section{Laboratory parameters}

Laboratory parameters are summarized in Table 1 and Table 2. Strongyloidiasis was diagnosed on first stool microscopy in most of the patients $(13,86.6 \%)$. Stool microscopy revealed ova of Strongyloides in a patient who also had acute renal

Table 1: Laboratory parameters of the patients

\begin{tabular}{|c|c|c|c|c|}
\hline Variables & $\begin{array}{l}\text { Immunocompetent } \\
\text { patients }(n=8)\end{array}$ & $\begin{array}{c}\text { Immunocompromised } \\
\text { patients }(\mathrm{n}=7)\end{array}$ & p value & Normal \\
\hline \multicolumn{4}{|c|}{ Clinical variables (Median and range) } & \\
\hline Age (years) & $41.50(14-52)$ & $22(3-66)$ & 0.37 & \\
\hline \multicolumn{4}{|c|}{ Laboratory variable (Median and range) } & \\
\hline $\begin{array}{l}\text { Hemoglobin } \\
\text { (g/dL) }\end{array}$ & $11.6(7.2-13.8)$ & $9(7.2-15.7)$ & 0.45 & $12-16$ \\
\hline TLC (cells/ $\mu L)$ & $8250(6000-19000)$ & $7800(2200-17600)$ & 0.91 & $4000-11000$ \\
\hline Neutrophil(cells/ $/ \mu \mathrm{L}$ ) & $5497(1826-8550)$ & $3520(2002-12060)$ & 0.73 & $2000-7500$ \\
\hline $\begin{array}{l}\text { Lymphocyte } \\
\text { (cells/ } / \mathrm{L} \text { ) }\end{array}$ & $2483.5(1080-6225)$ & $1312(176-13904)$ & 0.47 & $1500-4000$ \\
\hline $\begin{array}{l}\text { Eosinophil } \\
\text { (cells/mm³) }\end{array}$ & $254(0-6650)$ & $82(0-1296)$ & 0.06 & $0-400$ \\
\hline Eosinophilia* & 2 & 1 & 0.83 & - \\
\hline Monocyte (cells/ $\mu \mathrm{L})$ & $145(0-537)$ & $156(22-704)$ & 0.9 & $200-800$ \\
\hline ESR $(\mathrm{mm} / \mathrm{hr})$ & $20(5-72)$ & $20(2-66)$ & 0.93 & $0-15$ \\
\hline
\end{tabular}

*Absolute eosinophil count $>400$ cells $/ \mathrm{mm}^{3}$

Table 2: Comparison of clinical and laboratory parameters among immunocompetent and compromised patients

\begin{tabular}{|c|c|c|c|c|c|}
\hline s. No. & Age/Gender & Clinical Diagnosis & Hb & $\begin{array}{l}\mathrm{TLC}(\mathrm{x} 1000 \\
\text { cells/jL) }\end{array}$ & $\begin{array}{l}\text { Eosinophil } \\
\text { (cells/mms) }\end{array}$ \\
\hline 1 & 24/Male & Acule severe ulcerative colitis & 7.7 & 4.1 & 82 \\
\hline 2 & 54/Male & Symptomatic cholelithiasis & 13.4 & 8.2 & 328 \\
\hline 3 & 3/Male & Sepsis, hepatosplenomegaly & 8.6 & 17.6 & 176 \\
\hline 4 & 21/Male & Nephrotic syndrome & 7.2 & 13.4 & 0 \\
\hline 5 & 42/Female & $\begin{array}{l}\text { Cushing'sdiscase,pituitary } \\
\text { macroadenoma,DM }\end{array}$ & 10.1 & 11.4 & 114 \\
\hline 6 & 52/Male & Lumb adenoma & 7.2 & 6.2 & 372 \\
\hline 7 & 28/Male & Reactive arthritis & 11.5 & 17.9 & 6265 \\
\hline 8 & 48/Female & Malena & 11.8 & 7.1 & 0 \\
\hline 9 & 32/Male & Chronic dianthoea/Chronic HBV & 9.5 & 6 & 180 \\
\hline 10 & 41/Male & Strongyloidiasis & 13.8 & 19 & 6650 \\
\hline 11 & 66/Male & multiple colonic ulcer & 9 & 7.2 & 1296 \\
\hline 12 & 6/Female & Chronic diantica & 11 & 7.8 & 78 \\
\hline 13 & 49/Male & Sensorymotor quadraparesis & 15.7 & 9.4 & 188 \\
\hline 14 & 22/Male & HIV, recurrent dianthoea & 9.6 & 2.2 & 22 \\
\hline 15 & 14/Male & Solitary roctal uloer & 11.7 & 83 & 83 \\
\hline
\end{tabular}


failure ( Figure 1 and 2). Ova were of large size and had fully developed larvae. We could not dothe molecular characterization to confirm species identification of these ova. Duodenal biopsy showed normal histology in twelve (80\%), and partial villous atrophy in one $(6.7 \%)$ patient. Duodenal biopsy revealed larvae of Strongyloides in one patient. Enzyme linked immunosorbent assay (ELISA) for human immunodeficiency virus was positive in one patient. Giardia and Cryptosporidium were detected on stool microscopy in one patient each. Three patients had eosinophilia, of which, two were immunocompetent and one was immunocompromised. Strongyloides hyper-infection occurs in immunosuppressive states due to disease or therapy with corticosteroids and is characterized by invasion of extraintestinal sites like, lungs, liver, spleen, pancreas, gall bladder, kidneys, thyroid, brain, skin, and skeletal muscle. None of the patients had Strongyloides hyper-infection.

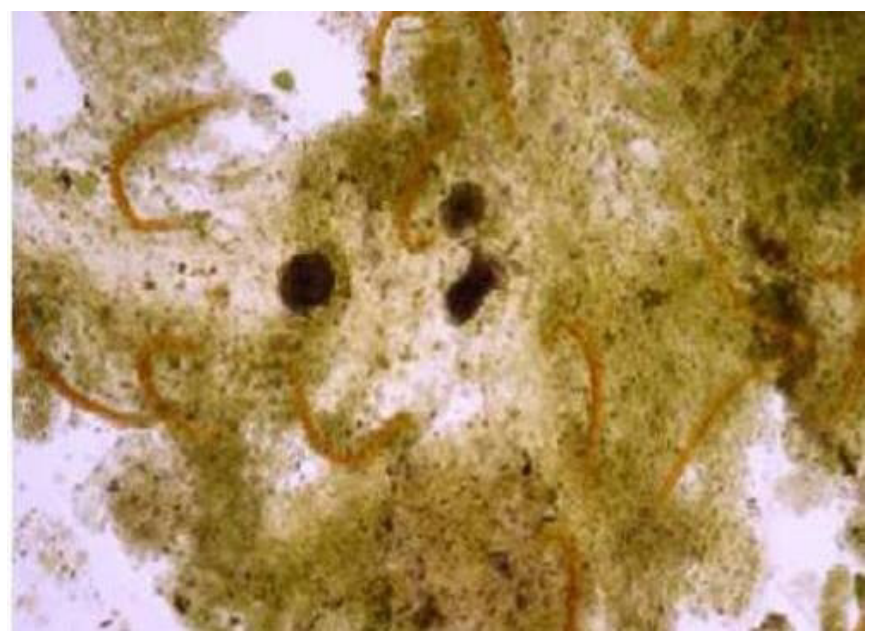

Figure 1: Lugol's Iodine stain of stool sample of a patient showing larva of Strongyloides stercoralis

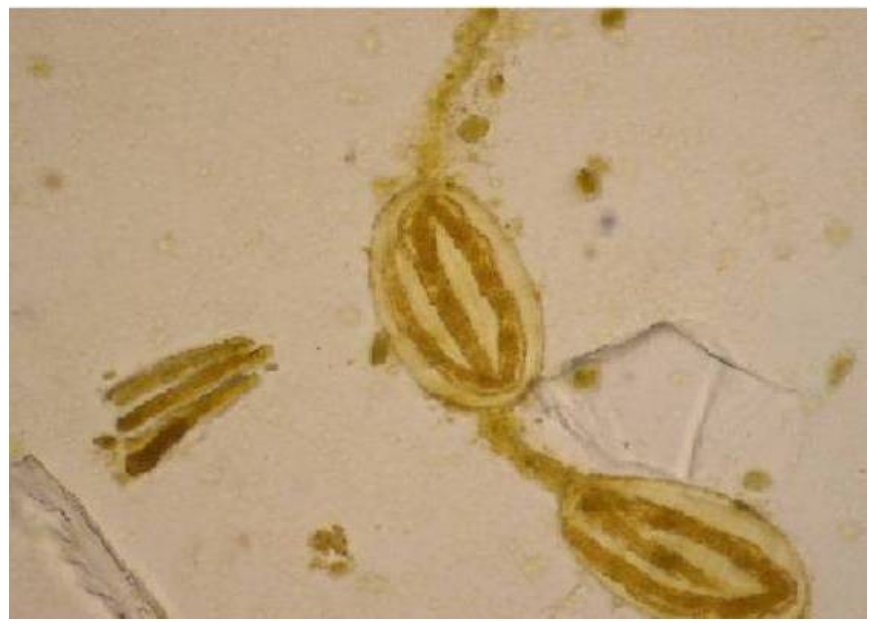

Figure 2: Lugol's Iodine stain of stool sample of a patient showing hatching stage of Strongyloides

\section{Treatment and follow-up}

Fourteen patients were treated with ivermectin (6 mg twice daily for 6 days in immunocompromised host and for 5 days in an immunocompetent host) and one with albendazole (400 mg twice daily for 3 days). Nine patients showed resolution of infection and disappearance of Strongyloides over a median follow-up period of 14 days (range 4-570), one died within five days after diagnosis and five were lost to follow-up.

\section{Discussion}

The present retrospective study showed that, (a) in endemic areas, even immunocompetent subjects may suffer from symptomatic strongyloidiasis, (b) eosinophilia is uncommon in strongyloidiasis, and (c) first stool examination detects the parasite in most patients with strongyloidiasis on properly conducted stool microscopy.

Strongyloidiasis, endemic in tropical and subtropical countries, is usually known to be asymptomatic. However, it can cause fatal hyper-infection in patients with immunocompromised status. In a study on 78 asymptomatic individuals from southern India, the prevalence rate of parasitic infections was reported to be $97.4 \%$, with Strongyloides infection rate of $20 \% .^{2}$ Similarly, in another community based study of 198 individuals from Assam, 17 (8.5\%) individuals were infected with Strongyloides, of which 10 (58.8\%) were reported to be asymptomatic. ${ }^{3}$ In our study, all patients were symptomatic and presented with chronic diarrhea, acute diarrhea, abdominal pain, weight loss, cough, vomiting and anemia. Similarly, in a study describing five patients with strongyloidiasis in an endemic area, all presented with gastrointestinal symptoms. ${ }^{4}$ In another study on 205 parasitic infected patients, 68 (33.2\%) had strongyloidiasis, of which $72 \%$ reported gastrointestinal symptoms. ${ }^{5}$ In addition to the above documentations there are other reports of patients infected with strongyloidiasis presenting with gastrointestinal symptoms. ${ }^{6-8}$ This suggests that clinicians should consider investigating for Strongyloides stercoralis infection even in immunocompetent patients presenting with suggestive gastrointestinal symptoms.

Strongyloides infection is known to be associated with peripheral blood eosinophilia in the immunocompetent host. However, this is considered unreliable in patients receiving corticosteroid therapy or those infected with human 
immunodeficiency virus (HIV). In an earlier report of $12 \%$ patients infected with strongyloidiasis, $66 \%$ presented with eosinophilia. ${ }^{9}$ There are other reports suggesting eosinophilia to be an important laboratory finding in patients infected with Strongyloides..$^{810-11}$ In contrast, we found eosinophilia to be rather uncommon even in immunocompetent individuals in our cohort. Absence of eosinophilia in immunocompromised patients diagnosed with strongyloidiasis has been reported in other studies. ${ }^{12-14}$ Hence, eosinophilia cannot be considered a reliable screening parameter for Strongyloides infection even in immunocompetent patients.

A single stool microscopy has been reported to be $30 \%$ sensitive for the diagnosis of intestinal Strongyloides infection. ${ }^{15}$ However, in our study $86.6 \%$ of the patients were diagnosed with strongyloidiasis on their first stool microscopy itself. This is similar to the finding of Grove et $\mathrm{al}^{16}$ who reported successful diagnosis of $68 \%$ patients with strongyloidiasis at the first stool microscopic examination. Furthermore, single stool microscopic examination has also been reported to reveal strongyloidiasis in a patient infected with AIDS. ${ }^{17}$ Therefore, first stool microscopic examination can be considered as an efficient technique for diagnosing strongyloidiasis.

The present study showed that most patients with Strongyloides infection to be male. The association was similar to that noted in previous studies. ${ }^{18-21}$ This high infection rate in males could be due to their outdoor work and hence higher probability of exposure to Strongyloides stercoralis infective stages. ${ }^{19}$ Another finding of the study was a higher Strongyloides infection rate in older age groups which was in concordance with findings of previous studies. ${ }^{19}$ This could be explained by the higher re-infection rates in the elderly.

We can conclude that, even immunocompetent individuals presenting with gastrointestinal symptoms should be considered for diagnosing Strongyloides infection even in the absence of eosinophilia. Detection of Strongyloides larva by direct stool microscopy is an efficient tool for diagnosing strongyloidiasis.

\section{References}

1. Vigg A, Mantri S, Reddy VA, Biyani V. Acute respiratory distress syndrome due to Strongyloides stercoralis in non-Hodgkin's lymphoma. Indian J Chest Dis Allied Sci. 2006;48:67-9.

2. Kang G, Mathew MS, Rajan DP, Daniel JD, Mathan MM, Mathan VI, et al. Prevalence of intestinal parasites in rural Southern Indians. Trop Med Int Health. 1998;3:70-5.
3. Devi U, Borkakoty B, Mahanta J. Strongyloidiasis in Assam, India: A community- based study. Trop Parasitol. 2011;1:30-2.

4. Agrawal V, Agarwal T, Ghoshal UC. Intestinal strongyloidiasis: a diagnosis frequently missed in the tropics. Trans $R$ Soc Trop Med Hyg. 2009;103:242-6.

5. Fisher D, McCarry F, Currie B. Strongyloidiasis in the Northern Territory. Under-recognised and under-treated? Med J Aust. 1993;159:88-90.

6. Tsai HC, Lee SS, Liu YC, Lin WR, Huang CK, Chen YS, et al. Clinical manifestations of strongyloidiasis in southern Taiwan. $J$ Microbiol Immunol Infect. 2002;35:29-36.

7. Werneck-Silva AL, Sipahi AM, Damiao AO, Buchpigue CA, Iriya $\mathrm{K}$, Laudanna AA. Intestinal permeability in strongyloidiasis. Braz J Med Biol Res. 2001;34:353-7.

8. Gonzalez A, Gallo M, Valls ME, Munoz J, Puyol L, Pinazo MJ, et al. Clinical and epidemiological features of 33 imported Strongyloides stercoralis infections. Trans R Soc Trop Med Hyg. 2010;104:613-6.

9. Gill GV, Welch E, Bailey JW, Bell DR, Beeching NJ. Chronic Strongyloides stercoralis infection in former British Far East prisoners of war. QJM. 2004;97:789-95.

10. de Silva S, Saykao P, Kelly H, MacIntyre CR, Ryan N, Leydon $\mathrm{J}$, et al. Chronic Strongyloides stercoralis infection in Laotian immigrants and refugees 7-20 years after resettlement in Australia. Epidemiol Infect. 2002;128:439-44.

11. Al-Hasan MN, McCormick M, Ribes JA. Invasive enteric infections in hospitalized patients with underlying strongyloidiasis. Am J Clin Pathol. 2007;128:622-7.

12. Ghoshal UC, Ghoshal U, Jain M, Kumar A, Aggarwal R, Misra A, et al. Strongyloides stercoralis infestation associated with septicemia due to intestinal transmural migration of bacteria. $J$ Gastroenterol Hepatol. 2002;17:1331-3.

13. Yee A, Boylen CT, Noguchi T, Klatt EC, Sharma OP. Fatal Strongyloides stercoralis infection in a patient receiving corticosteroids. West J Med. 1987;146:363-4.

14. Harcourt-Webster JN, Scaravilli F, Darwish AH. Strongyloides stercoralis hyperinfection in an HIV positive patient. J Clin Pathol. 1991;44:346-8.

15. Siddiqui AA, Berk SL. Diagnosis of Strongyloides stercoralis infection. Clin Infect Dis. 2001;33:1040-7.

16. Grove DI. Strongyloidiasis in Allied ex-prisoners of war in southeast Asia. Br Med J. 1980;280:598-601.

17. Sing A, Leitritz L, Bogner JR, Heesemann J. First-glance diagnosis of Strongyloides stercoralis autoinfection by stool microscopy. $J$ Clin Microbiol. 1999;37:1610-1.

18. Sudarshi S, Stumpfle R, Armstrong M, Ellman T, Parton S, Krishnan P, et al. Clinical presentation and diagnostic sensitivity of laboratory tests for Strongyloides stercoralis in travellers compared with immigrants in a non-endemic country. Trop Med Int Health. 2003;8:728-32.

19. Jongsuksuntigul P, Intapan PM, Wongsaroj T, Nilpan S, Singthong S, Veerakul S, et al. Prevalence of Strongyloides stercoralis infection in northeastern Thailand (agar plate culture detection). J Med Assoc Thai. 2003;86:737-41.

20. Roman-Sanchez P, Pastor-Guzman A, Moreno-Guillen S, IgualAdell R, Suner-Generoso S, Tornero-Estebanez C. High prevalence 
of Strongyloides stercoralis among farm workers on the Mediterranean coast of Spain: analysis of the predictive factors of infection in developed countries. Am J Trop Med Hyg. 2003;69:336-40.
21. Chordia P, Christopher S, Abraham OC, Muliyil J, Kang G, Ajjampur S. Risk factors for acquiring Strongyloides stercoralis infection among patients attending a tertiary hospital in south India. Indian J Med Microbiol. 2011;29:147-51. 